\title{
Article \\ Biosynthesis of Polyhydroxyalkanoates from Defatted Chlorella Biomass as an Inexpensive Substrate
}

\author{
Chanin Khomlaem (D), Hajer Aloui (D) and Beom Soo Kim * (D) \\ Department of Chemical Engineering, Chungbuk National University, Cheongju, Chungbuk 28644, Korea; \\ namiien2t@chungbuk.ac.kr (C.K.); hajer.al@chungbuk.ac.kr (H.A.) \\ * Correspondence: bskim@chungbuk.ac.kr; Tel.: +82-43-261-2372; Fax: +82-43-269-2370
}

\section{check for}

updates

Citation: Khomlaem, C.; Aloui, H.; Kim, B.S. Biosynthesis of Polyhydroxyalkanoates from Defatted Chlorella Biomass as an Inexpensive Substrate. Appl. Sci. 2021, 11, 1094. https://doi.org/10.3390/ app11031094

Received: 30 December 2020

Accepted: 20 January 2021

Published: 25 January 2021

Publisher's Note: MDPI stays neutral with regard to jurisdictional claims in published maps and institutional affiliations.

Copyright: (c) 2021 by the authors. Licensee MDPI, Basel, Switzerland. This article is an open access article distributed under the terms and conditions of the Creative Commons Attribution (CC BY) license (https:/ / creativecommons.org/licenses/by/ $4.0 /)$.

\begin{abstract}
Microalgae biomass has been recently used as an inexpensive substrate for the industrial production of polyhydroxyalkanoates (PHAs). In this work, a dilute acid pretreatment using $0.3 \mathrm{~N}$ of hydrochloric acid $(\mathrm{HCl})$ was performed to extract reducing sugars from $10 \%(w / v)$ of defatted Chlorella biomass (DCB). The resulting $\mathrm{HCl}$ DCB hydrolysate was used as a renewable substrate to assess the ability of three bacterial strains, namely Bacillus megaterium ALA2, Cupriavidus necator KCTC 2649, and Haloferax mediterranei DSM 1411, to produce PHA in shake flasks. The results show that under $20 \mathrm{~g} / \mathrm{L}$ of DCB hydrolysate derived sugar supplementation, the cultivated strains successfully accumulated PHA up to $29.7-75.4 \%$ of their dry cell weight (DCW). Among the cultivated strains, C. necator KCTC 2649 exhibited the highest PHA production $(7.51 \pm 0.20 \mathrm{~g} / \mathrm{L}, 75.4 \%$ of DCW $)$ followed by H. mediterranei DSM 1411 and B. megaterium ALA2, for which a PHA content of $3.79 \pm 0.03 \mathrm{~g} / \mathrm{L}(55.5 \%$ of DCW) and $0.84 \pm 0.06 \mathrm{~g} / \mathrm{L}(29.7 \%$ of DCW) was recorded, respectively. Along with PHA, a maximum carotenoid content of $1.80 \pm 0.16 \mathrm{mg} / \mathrm{L}$ was produced by $H$. mediterranei DSM 1411 at $120 \mathrm{~h}$ of cultivation in shake flasks. PHA and carotenoid production increased by 1.45- and 1.37-fold, respectively, when $\mathrm{HCl}$ DCB hydrolysate biotransformation was upscaled to a $1 \mathrm{~L}$ of working volume fermenter. Based on FTIR and ${ }^{1} \mathrm{H}$ NMR analysis, PHA polymers accumulated by B. megaterium ALA2 and C. necator KCTC 2649 were identified as homopolymers of poly(3-hydroxybutyrate). However, a copolymer of poly(3-hydroxybutyrate-co-3-hydroxyvalerate) with a 3-hydroxyvalerate fraction of $10.5 \mathrm{~mol} \%$ was accumulated by H. mediterranei DSM 1411.
\end{abstract}

Keywords: Acid pretreatment; Bacillus megaterium; Carotenoids; Cupriavidus necator; Defatted Chlorella biomass; Haloferax mediterranei; Polyhydroxyalkanoates

\section{Introduction}

Petrochemical-based materials have gained particular attention in various fields due to their excellent properties, such as good mechanical resistance and high thermal stability. However, being non-biodegradable, the accumulation of these materials may produce adverse effects on environmental and public health [1]. Recently, biodegradable polymers derived from microbial fermentation have been investigated as promising alternatives to help reduce plastic waste disposal in the environment. Among a variety of bioplastics, polyhydroxyalkanoates (PHAs) produced through microbial fermentation have received particular interest owing to their low toxicity, biocompatibility, complete biodegradability, and competitive properties compared with conventional plastics [2]. Despite their excellent properties and environmental benefits, the industrial production of PHA is somehow restricted due to the use of highly purified substrates that may entail high costs. Therefore, many studies have investigated the use of residue raw materials such as rice bran [3], lignocellulosic biomass [4], waste cooking oils [5], and coffee waste [6] as inexpensive fermentation substrates to reduce the PHA production cost.

Among a variety of waste materials, biomass from macro- and microalgae has shown great potential as a promising candidate for the industrial production of bioplastics due to 
its high carbohydrate content and negligible lignin amount giving rise to high reducing sugar recovery without any costly lignin removal [7]. Moreover, the utilization of algal biomass as a substrate for PHA production may reduce food waste utilization, which may entail ethical issues related to the interference with human nutrition and animal feeding.

Dilute acid hydrolysis has been widely used for the pretreatment of algal biomass owing to its ability to enhance the conversion efficiency of carbohydrates into reducing sugars [8]. Previously, high fermentable sugar contents of $29 \mathrm{~g} / \mathrm{L}$ and $52 \mathrm{~g} / \mathrm{L}$ were respectively reported by Alkotaini et al. [9] and Khomlaem et al. [10] as a result of subjecting either Laminaria japonica or defatted Chlorella biomass to dilute acid hydrolysis using $94 \mathrm{mM}$ of sulfuric acid $\left(\mathrm{H}_{2} \mathrm{SO}_{4}\right)$ and $0.3 \mathrm{~N}$ of hydrochloric acid $(\mathrm{HCl})$, respectively.

Chlorella (chlorophyte, Trebouxiophyceae) is considered to be one of the most cultivated microalgae in the world, providing more than 2000 tons of annual biomass production, and has been widely used as feed and food raw material owing to its high content of proteins, short-chain polyunsaturated fatty acids, vitamins, and minerals [11]. In the last few years, defatted Chlorella biomass (DCB) has received a particular interest as an excellent feedstock for bioethanol production [12,13] owing to its high content of carbohydrates either present in the form of hemicellulose and cellulose in the cell wall or accumulated in the form of starch in the chloroplast [14]. Recently, our research group has claimed the potential use of Chlorella biomass as a promising substrate for the production of PHA owing to its high carbohydrate content (69.5\%) and has reported a maximum PHA production of $3.62 \mathrm{~g} / \mathrm{L}$ (39.4\% of dry cell weight) when Paracoccus sp. LL1 was cultivated in a minimal medium supplemented with $20 \mathrm{~g} / \mathrm{L}$ of DCB-hydrolysate-derived sugars [10].

Among a variety of PHA-accumulating bacteria, Bacillus megaterium ALA2, Cupriazidus necator KCTC 2649, and Haloferax mediterranei DSM 1411 strains have shown great potential in producing high PHA contents through the bioconversion of algae biomass $[7,9,15]$. In this work, a dilute acid pretreatment using $0.3 \mathrm{~N}$ of $\mathrm{HCl}$ was performed to extract reducing sugars from $10 \%(w / v)$ of DCB. The resulting $\mathrm{HCl}$ DCB hydrolysate was investigated as a sustainable substrate to assess the ability of three bacterial strains, namely $B$. megaterium ALA2, C. necator KCTC 2649, and H. mediterranei DSM 1411 to produce PHA in shake flasks. Along with PHA, the ability of H. mediterranei DSM 1411 in producing carotenoids was also investigated at both flask and fermenter scale.

\section{Materials and Methods}

\subsection{Chemicals and Microalgae Biomass}

Chemicals including astaxanthin, poly (3-hydroxybutyrate-co-3-hydroxyvalerate) ( $\mathrm{P}$ (3HB-co-3HV)), and poly(3-hydroxybutyrate) (PHB) were purchased from Sigma-Aldrich, while DCB was obtained from the Korea Research Institute of Bioscience and Biotechnology. Algal biomass used as a substrate in this work was prepared according to Khomlaem et al. [10].

\subsection{Microbial Strains}

Three microbial strains, namely Bacillus megaterium ALA2 (NRRL B-21660) (originally isolated from a soil sample collected from McCalla, AL [16]), Cupriavidus necator KCTC 2649 (purchased from the Korean Collection for Type Cultures (Daejeon, Korea)), and Haloferax mediterranei DSM 1411 (purchased from the DSMZ culture collection (Braunschweig, Germany)) were evaluated for their PHA-accumulation ability when using $\mathrm{HCl}$ $\mathrm{DCB}$ as a fermentative substrate. The strains grown on Luria-Bertani (LB) agar were stored at $4{ }^{\circ} \mathrm{C}$.

\subsection{Media Preparation}

A minimal medium [10] composed of $9 \mathrm{~g} / \mathrm{L}$ of $\mathrm{Na}_{2} \mathrm{HPO}_{4} \times 12 \mathrm{H}_{2} \mathrm{O}, 0.5 \mathrm{~g} / \mathrm{L}$ of $\mathrm{KH}_{2} \mathrm{PO}_{4}$ $1 \mathrm{~g} / \mathrm{L}$ of $\left(\mathrm{NH}_{4}\right)_{2} \mathrm{SO}_{4}, 1 \mathrm{~g} / \mathrm{L}$ of $\mathrm{MgSO}_{4} \times 7 \mathrm{H}_{2} \mathrm{O}, 20 \mathrm{mg} / \mathrm{L}$ of $\mathrm{CaCl}_{2} \times 2 \mathrm{H}_{2} \mathrm{O}, 10 \mathrm{~g} / \mathrm{L}$ of NaCl , and $2 \mathrm{~mL} / \mathrm{L}$ of trace element solution under $20 \mathrm{~g} / \mathrm{L}$ of fermentable sugar supplementation from $0.3 \mathrm{~N} \mathrm{HCl}$ DCB hydrolysate was used for B. megaterium ALA2 cultivation in shake 
flasks. The same medium devoid of $\mathrm{NaCl}$ was used for C. necator KCTC 2649 to accumulate PHA in shake flasks. The trace element solution was composed of $0.44 \mathrm{~g} / \mathrm{L}$ of $\mathrm{ZnCl}_{2} \times$ $7 \mathrm{H}_{2} \mathrm{O}, 4.98 \mathrm{~g} / \mathrm{L}$ of $\mathrm{FeSO}_{4} \times 7 \mathrm{H}_{2} \mathrm{O}, 0.78 \mathrm{~g} / \mathrm{L}$ of $\mathrm{CuSO}_{4} \times 5 \mathrm{H}_{2} \mathrm{O}, 0.81 \mathrm{~g} / \mathrm{L}$ of $\mathrm{MnSO}_{4} \times 4 \mathrm{H}_{2} \mathrm{O}$, and $0.24 \mathrm{~g} / \mathrm{L}$ of $\mathrm{Na}_{2} \mathrm{MoO}_{4} \times 2 \mathrm{H}_{2} \mathrm{O}$ dissolved in $1 \mathrm{~N} \mathrm{HCl}$ solution [10].

A Halobacterium medium composed of $13 \mathrm{~g} / \mathrm{L}$ of $\mathrm{MgCl}_{2} \times 6 \mathrm{H}_{2} \mathrm{O}, 156 \mathrm{~g} / \mathrm{L}$ of NaCl , $20 \mathrm{~g} / \mathrm{L}$ of $\mathrm{MgSO}_{4} \times 7 \mathrm{H}_{2} \mathrm{O}, 4 \mathrm{~g} / \mathrm{L}$ of $\mathrm{KCl}, 1 \mathrm{~g} / \mathrm{L}$ of $\mathrm{CaCl}_{2} \times 6 \mathrm{H}_{2} \mathrm{O}, 0.5 \mathrm{~g} / \mathrm{L}$ of $\mathrm{NaBr}, 0.2 \mathrm{~g} / \mathrm{L}$ of $\mathrm{NaHCO}_{3}$, and $5 \mathrm{~g} / \mathrm{L}$ of yeast extract [17] supplemented with $20 \mathrm{~g} / \mathrm{L}$ of DCB-hydrolysatederived sugars was used to assess the ability of $H$. mediterranei DSM 1411 to co-produce PHAs and carotenoids at both shake flask and fermenter scale.

\subsection{Algal Biomass Pretreatment and Reducing Sugar Quantification}

A dilute acid pretreatment using $0.3 \mathrm{~N}$ of $\mathrm{HCl}$ was performed to extract reducing sugars from $10 \%(w / v)$ of DCB according to the method used by Khomlaem et al. [10]. After centrifugation at $10,950 \times g$ for $20 \mathrm{~min}$, the resulting supernatant was used for reducing sugar quantification based on the 3,5-dinitrosalicylic acid (DNS) method.

Acid type and concentration were selected based on our previous study reporting the efficacy of this acid pretreatment to achieve a maximum fermentable sugar level of $52 \mathrm{~g} / \mathrm{L}$. The recovered reducing sugars were identified by HPLC analysis as glucose $(46 \mathrm{~g} / \mathrm{L})$ and cellobiose $(5.94 \mathrm{~g} / \mathrm{L})$ [10].

\subsection{PHA Production via Batch Cultivation in Shake Flasks}

The shake flask cultivation of three bacterial strains including B. megaterium ALA2, C. necator KCTC 2649, and H. mediterranei DSM 1411 was performed to screen their PHAaccumulating ability.

Flask cultures were carried out in $200 \mathrm{~mL}$ of a minimal medium under $20 \mathrm{~g} / \mathrm{L}$ of reducing sugar supplementation from sterilized HCL DCB hydrolysate. The temperature was set at $30^{\circ} \mathrm{C}$ for B. megaterium ALA2 and C. necator KCTC 2649, while a temperature of $42{ }^{\circ} \mathrm{C}$ was used for the cultivation of $H$. mediterranei DSM 1411. Flask cultures were shaken at $200 \mathrm{rpm}$ in a rotary incubator.

\subsection{Analytical Techniques}

2.6.1. Determination of Cell Growth and Dry Cell Weight (DCW)

Microbial growth was determined by optical density at $600 \mathrm{~nm}$. DCW was determined according to Khomlaem et al. [10]. For each bacterial culture, DCW was measured gravimetrically at a $24-\mathrm{h}$ interval.

\subsubsection{Reducing Sugar Quantification during the Fermentation Process}

The DNS method was used to quantify residual reducing sugar content as previously described by Khomlaem et al. [10].

\subsubsection{Quantification of Intracellular PHA and Carotenoid Content}

A methanolysis-gas chromatography (Agilent model 6890N, Agilent, Santa Clara, CA, USA) analysis was performed to quantify PHA as previously detailed by Khomlaem et al. [10]. Benzoic acid and P (3HB-co-3HV), containing $88 \mathrm{~mol} \%$ of $3 \mathrm{HB}$ and $12 \mathrm{~mol} \%$ of $3 \mathrm{HV}$, respectively, were used as standards.

Carotenoid content was quantified based on the method described by Khomlaem et al. [10].

\subsection{PHA Characterization}

PHAs accumulated inside bacterial cells were characterized by FTIR and ${ }^{1} \mathrm{H}$ NMR analysis.

A Nicolet model Magna-IR 200 FTIR spectrometer (Thermo Fisher Scientific, Waltham, MA, USA) was used to collect FTIR spectra of the accumulated PHA polymers in a spectral range of $4000-400 \mathrm{~cm}^{-1}$. 
A ${ }^{1} \mathrm{H}$ NMR (Bruker Avance $500 \mathrm{MHz}$, Bruker BioSpin, Rheinstetten, Germany) analysis was performed to identify the molecular structure of the produced PHA as previously described by Muhammad et al. [15].

\subsection{Upscaling of PHA and Carotenoid Co-Production by H. mediterranei in a Fermenter}

H. mediterranei DSM 1411 batch cultivation was performed in a $1 \mathrm{~L}$ working volume fermenter to further improve PHA and carotenoid production. For this purpose, $20 \mathrm{~g} / \mathrm{L}$ of fermentable sugar derived from $\mathrm{HCl}$ DCB hydrolysate was added to the medium. The inoculum size was $10 \% v / v$. The agitation speed was adjusted to $300 \mathrm{rpm}$. The dissolved oxygen (DO) level was maintained beyond $20 \%$. The temperature and $\mathrm{pH}$ were respectively adjusted to $42{ }^{\circ} \mathrm{C}$ and 7.2 .

\section{Results and Discussion}

\subsection{PHA Production via Batch Cultivation in Shake Flasks}

The cell growth profile, PHA production, and substrate consumption by B. megaterium ALA2 during the fermentation process are shown in Figure 1. The reducing sugar concentration in DCB $\mathrm{HCl}$ hydrolysate-supplemented media decreased with increasing biomass production, giving rise to a maximum DCW of $2.81 \pm 0.05 \mathrm{~g} / \mathrm{L}$ at $72 \mathrm{~h}$ of cultivation. PHA production occurred concomitantly with cell growth and achieved a maximum of $0.84 \pm 0.06 \mathrm{~g} / \mathrm{L}(29.7 \%$ of DCW). Lower DCW $(1.80 \mathrm{~g} / \mathrm{L})$ and PHA $(0.40 \mathrm{~g} / \mathrm{L}, 21 \%$ of DCW $)$ levels were previously reported by Muhammad et al. [15] when B. megaterium ALA2 was cultivated in minimal media supplemented with Laminaria japonica hydrolysate. Such a difference in DCW and PHA yield can be explained by the difference in reducing sugar composition between the two hydrolysates. Previously, Gouda et al. [18] investigated the effect of different carbon sources, including maltose, fructose, Na-gluconate, glucose, lactose, xylose, and sucrose, on PHA accumulation by B. megaterium. The maximum production in terms of PHA was recorded in media supplemented with $2 \%$ glucose, which indicates the suitability of this carbon source for B. megaterium. Based on our previous study, glucose was identified as the main reducing sugar in $\mathrm{DCB} \mathrm{HCl} \mathrm{hydrolysate} \mathrm{[10],} \mathrm{which} \mathrm{may} \mathrm{explain,}$ in part, the higher level of PHA that accumulated inside B. megaterium ALA2 cells in this study, compared with that produced from Laminaria japonica hydrolysate [15] for which mannitol was identified as the main carbohydrate [19].

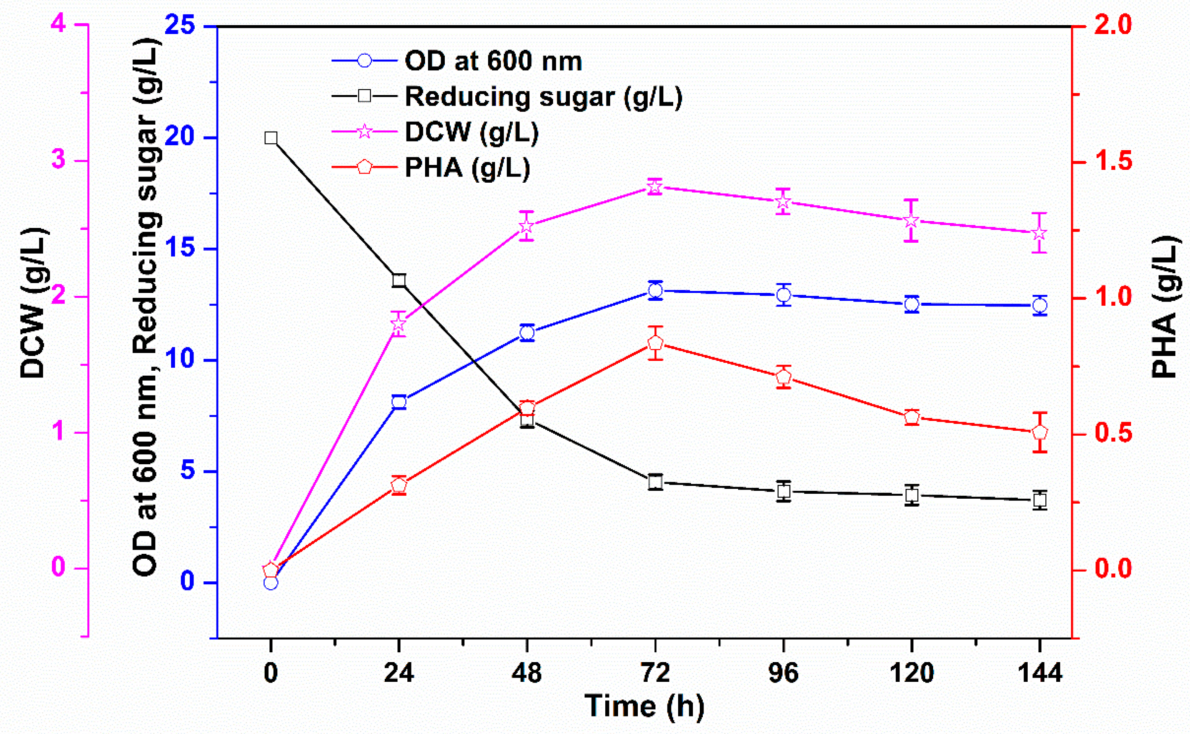

Figure 1. Time profile of optical density (OD) at $600 \mathrm{~nm}$, dry cell weight (DCW), polyhydroxyalkanoate (PHA) accumulation, and substrate utilization by Bacillus megaterium ALA2 using $0.3 \mathrm{~N} \mathrm{HCl}$ defatted Chlorella biomass (DCB) hydrolysate as the carbon source in a flask culture. Data are shown as mean values \pm standard deviation $(n=3)$. 
Figure 2 shows the cell growth profile, PHA production, and substrate consumption by C. necator KCTC 2649 during batch cultivation in shake flasks. Reducing sugar consumption increased with increasing bacterial growth. PHA accumulation started during the exponential phase and gradually increased during the stationary phase, giving rise to a maximum polymer content of $7.51 \pm 0.20 \mathrm{~g} / \mathrm{L}(75.4 \% \mathrm{of} D C W)$ at $120 \mathrm{~h}$ of cultivation due to PHA accumulation inside bacterial cells. In fact, during the stationary phase, cells cease division but remain metabolically active and start accumulating PHA under the excess of carbon source and nitrogen-limiting conditions [20]. The PHA level decreased after this time due to PHA utilization for cell maintenance purposes. PHA accumulation by C. necator in this work was significantly higher than that reported by Muhammad et al. [15] when cultivating C. necator NCIMB 11599 in a minimal medium supplemented with $2 \%$ of L. japonica acid hydrolysate ( $1.58 \mathrm{~g} / \mathrm{L} ; 32 \%$ of DCW). Likewise, a PHA production of only $0.62 \mathrm{~g} / \mathrm{L}$ was previously reported by Verlinden et al. [21] when C. necator was cultivated in a basal salt medium supplemented with waste rapeseed oil. Interestingly, the PHA content accumulated by $C$. necator in this work was significantly higher than that produced by the same strain cultivated in a mineral salt medium supplemented with $1 \%$ glucose, for which a maximum PHA production of only $1.61 \mathrm{~g} / \mathrm{L}$ ( $57.07 \%$ of dry cell weight) was recorded [22]. This result underlines the importance of using DCB hydrolysate as a promising low-cost substrate for industrial bioplastics production.

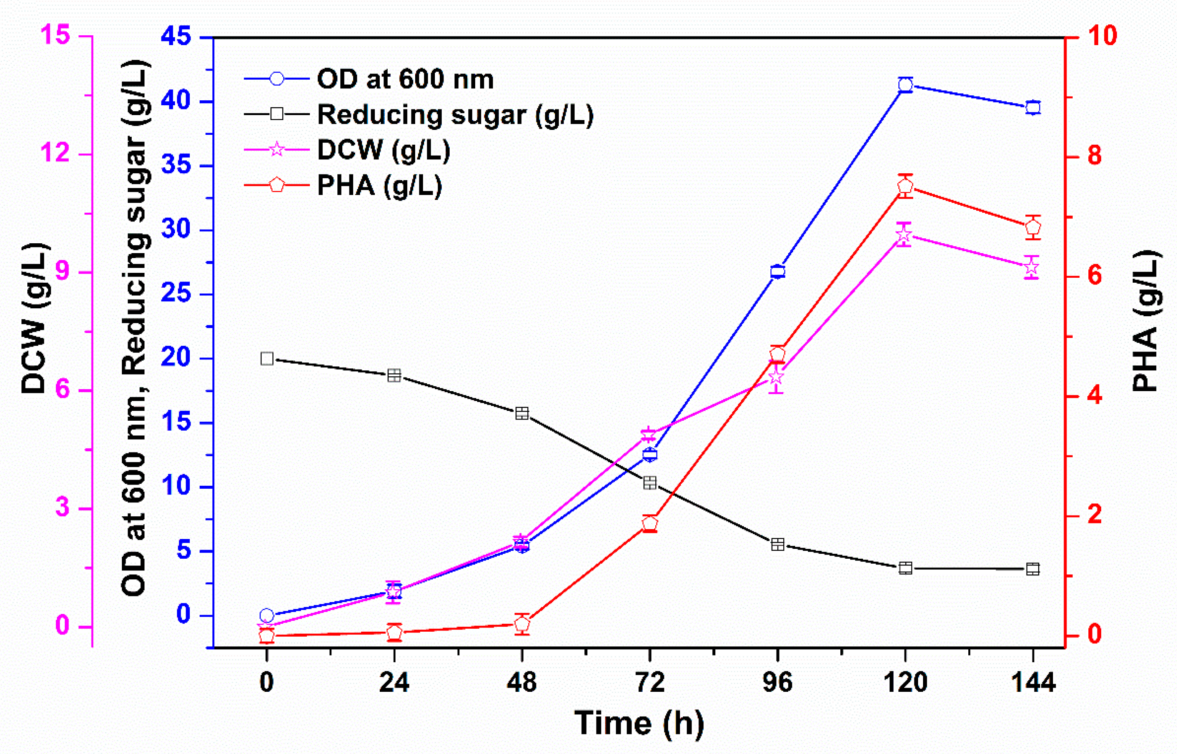

Figure 2. Time profile of OD at $600 \mathrm{~nm}$, DCW, PHA accumulation, and substrate utilization by Cupriavidus necator KCTC 2649 using $0.3 \mathrm{~N} \mathrm{HCl} \mathrm{DCB} \mathrm{hydrolysate} \mathrm{as} \mathrm{the} \mathrm{carbon} \mathrm{source} \mathrm{in} \mathrm{a} \mathrm{flask}$ culture. Data are shown as mean values \pm standard deviation $(n=3)$.

The cell growth profile, PHA accumulation, carotenoid production, and substrate utilization by $H$. mediterranei DSM 1411 cultivation during the fermentation process are shown in Figure 3. The reducing sugar content gradually decreased with time due to cell growth, denoting the ability of the cultivated strain to assimilate reducing sugars from $\mathrm{HCl}$ DCB hydrolysate. A continuous increase in DCW and PHA content was noticed during the exponential phase, achieving a maximum of $6.84 \pm 0.15 \mathrm{~g} / \mathrm{L}$ and $3.79 \pm 0.03 \mathrm{~g} / \mathrm{L}(55.5 \%$ of $\mathrm{DCW}$ ) respectively at $120 \mathrm{~h}$ of cultivation. Along with PHA accumulation, a maximum carotenoid content of $1.80 \pm 0.16 \mathrm{mg} / \mathrm{L}$ was obtained. The PHA production achieved by $H$. mediterranei DSM 1411 in this work was significantly higher than that accumulated by the same strain cultivated in a minimal synthetic medium (MSM) supplemented with emulsified volatile fatty acids, for which a maximum PHA content of $0.93 \mathrm{~g} / \mathrm{L}(37.4 \%$ of DCW) was recorded [23]. Likewise, the DCW and PHA levels recorded in this study were respectively $71 \%$ and $156 \%$ higher than those obtained by Khomlaem et al. [10] 
when using the same HCl DCB hydrolysate as a carbon source by Paracoccus sp. LL1. Among halophiles, haloarchaeon $H$. mediterranei has been reported to be the most efficient in accumulating PHA at high cell densities owing to its fast growth rate, genetic stability, and efficient metabolic capacity [24]. Several studies have reported the ability of this strain to produce high PHA levels through the conversion of different waste products, including cheese whey [25], rice-based ethanol stillage [26], and macroalgal biomass [7].

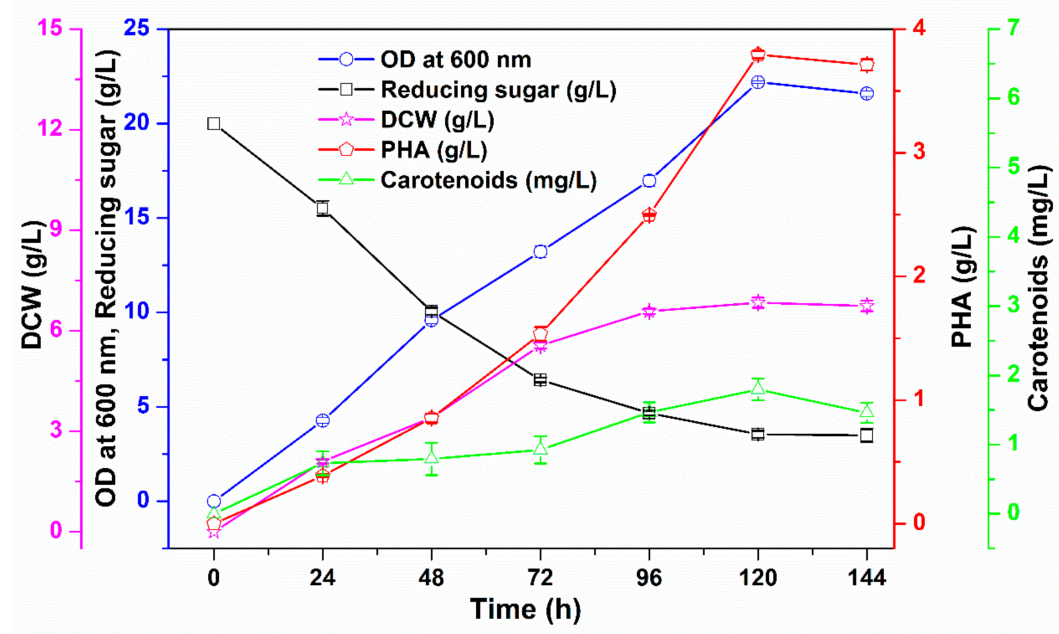

Figure 3. Time profile of OD at $600 \mathrm{~nm}$, DCW, PHA accumulation, carotenoid production, and substrate utilization by Haloferax mediterranei DSM 1411 using $0.3 \mathrm{~N} \mathrm{HCl} \mathrm{DCB} \mathrm{hydrolysate} \mathrm{as} \mathrm{the}$ carbon source in a flask culture. Data are shown as mean values \pm standard deviation $(n=3)$.

\subsection{Characterization of PHA Polymers}

\subsubsection{FTIR Analysis}

The FTIR spectra of PHA polymers accumulated by B. megaterium ALA2, C. necator KCTC 2649, and H. mediterranei DSM 1411 are shown in Figure 4. PHA polymers produced by the different bacterial strains showed characteristic bands of ester bonding present in PHB homopolymer at 1734 and $1185 \mathrm{~cm}^{-1}$ [27]. The FTIR spectrum of PHA polymers produced by H. mediterranei DSM 1411 showed additional peaks between 1450 and $1000 \mathrm{~cm}^{-1}$ corresponding to $\mathrm{CH}_{2}$ wagging, $\mathrm{CH}_{3}$ bending, $\mathrm{C}-\mathrm{O}, \mathrm{C}-\mathrm{C}$ and $\mathrm{C}-\mathrm{O}-\mathrm{C}$ stretching, confirming the $\mathrm{P}(3 \mathrm{HB}-c o-3 \mathrm{HV})$ nature of the sample [28]. Raho et al. [29] reported the same bands for $\mathrm{P}$ (3HB-co-3HV) produced from ricotta cheese exhausted whey.

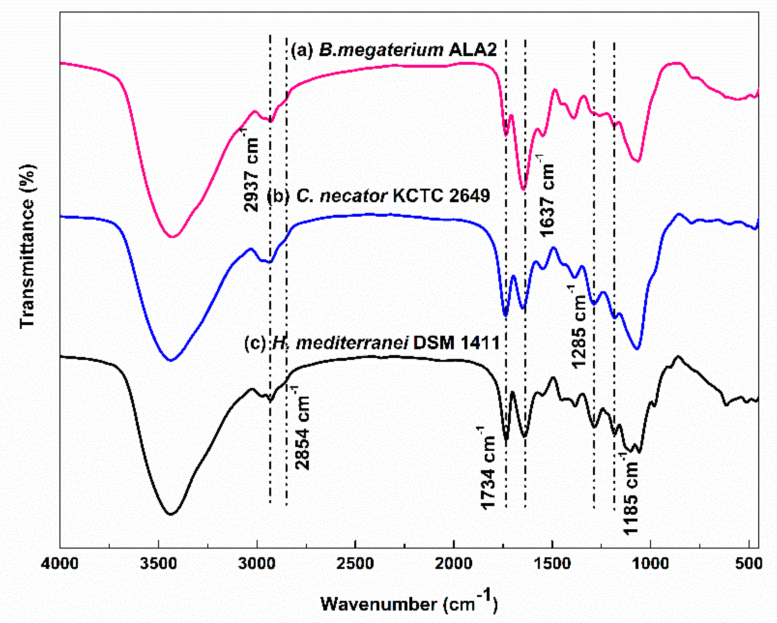

Figure 4. The FTIR spectra of PHA produced by (a) Bacillus megaterium ALA2, (b) Cupriavidus necator KCTC 2649, and (c) Haloferax mediterranei DSM 1411 using $0.3 \mathrm{~N} \mathrm{HCl} \mathrm{DCB} \mathrm{hydrolysate} \mathrm{as} \mathrm{the} \mathrm{carbon} \mathrm{source.}$ 


\subsection{2. ${ }^{1} \mathrm{H}$ NMR}

The ${ }^{1} \mathrm{H}$ NMR spectra of PHA polymers accumulated by B. megaterium ALA2 and C. necator KCTC 2649 showed three groups of peaks characteristic of PHB homopolymer, including the $\mathrm{CH}_{3}$ group at $1.29 \mathrm{ppm}$, the $\mathrm{CH}_{2}$ group at $2.57 \mathrm{ppm}$, and the $\mathrm{CH}$ group at $5.27 \mathrm{ppm}$ (Figure $5 \mathrm{a}, \mathrm{b})$. Similar ${ }^{1} \mathrm{H}$ NMR patterns were previously recorded for PHB produced by either B. megaterium ALA2 or C. necator KCTC 2649 when using brown algae (Sargassum sp.) hydrolysate and glucose as carbon sources, respectively $[8,30]$.

(a)

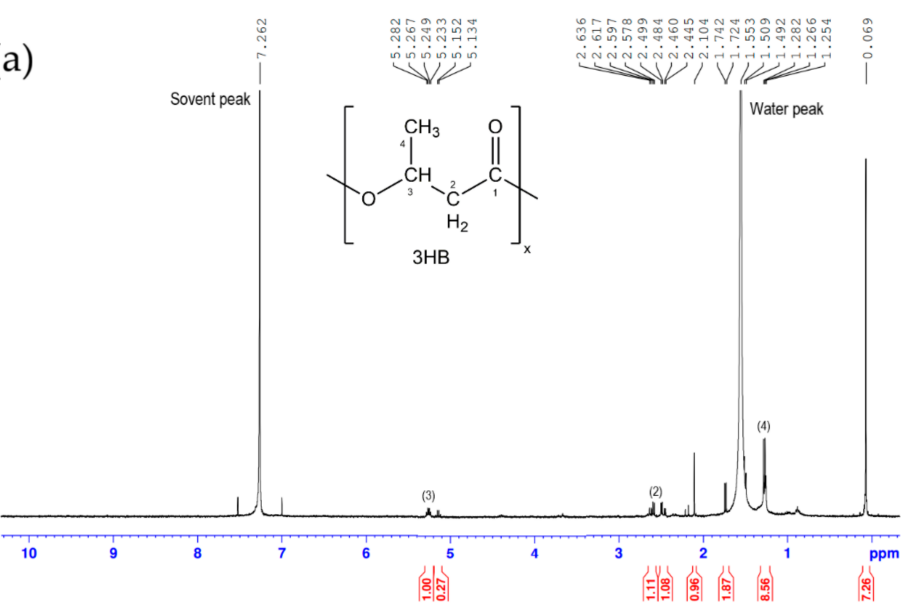

(b)
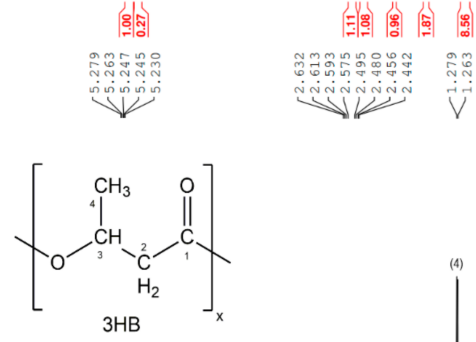

(c)

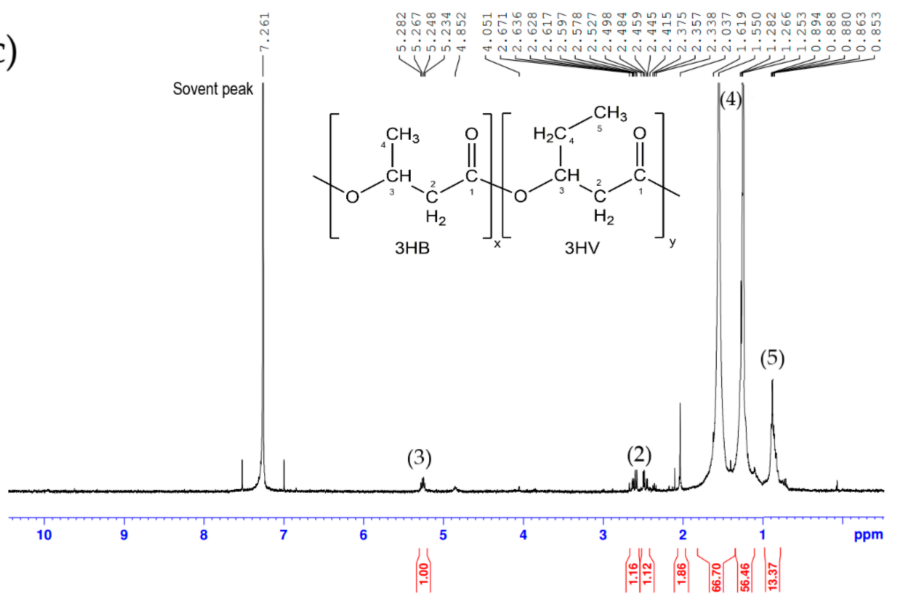

Figure 5. The ${ }^{1} \mathrm{H}$ NMR spectra of PHA produced by (a) Bacillus megaterium ALA2, (b) Cupriavidus necator KCTC 2649, and (c) Haloferax mediterranei DSM 1411 using $0.3 \mathrm{~N} \mathrm{HCl} \mathrm{DCB} \mathrm{hydrolysate} \mathrm{as} \mathrm{the}$ carbon source. 
With respect to PHA polymers produced by H. mediterranei DSM 1411, the ${ }^{1} \mathrm{H}$ NMR spectrum clearly shows two additional peaks at $0.9 \mathrm{ppm}$ and $1.6 \mathrm{ppm}$ respectively corresponding to the methyl and methylene groups of the valerate monomer, denoting that the produced PHA is a $\mathrm{P}$ (3HB-co-3HV) copolymer (Figure $5 \mathrm{c}$ ). Similar peaks were identified in the ${ }^{1} \mathrm{H}$ NMR spectra of the $\mathrm{P}(3 \mathrm{HB}-\mathrm{co}-3 \mathrm{HV})$ copolymer produced from macroalgal biomass hydrolysate [31]. The 3HV molar fraction in the $\mathrm{P}(3 \mathrm{HB}-\mathrm{co}-3 \mathrm{HV})$ copolymer was calculated from the area ratio of methyl group peaks corresponding to $3 \mathrm{HB}$ and $3 \mathrm{HV}$ units (1.27 and $0.9 \mathrm{ppm}$, respectively). Based on this calculation, the $3 \mathrm{HV}$ molar fraction was present in a ratio of $10.5 \mathrm{~mol} \%$. This $3 \mathrm{HV}$ ratio was higher than that recorded for the $\mathrm{P}(3 \mathrm{HB}-\mathrm{co}-$ $3 \mathrm{HV}$ ) copolymer accumulated by $H$. mediterranei from different carbon sources, including Ulva sp. macroalgae hydrolysate [7], hydrolyzed whey permeate [32], and glucose and yeast extract [33]. Likewise, the $3 \mathrm{HV}$ content obtained in this study was $68.8 \%$ higher than that recorded in our previous work when the same carbon source (DCB hydrolysate) was used by Paracoccus sp. LL1 [10]. Comparable 3HV content was previously recorded for the $\mathrm{P}$ (3HB-co-3HV) copolymer accumulated by Paracoccus sp. LL1 cultivated in a minimal medium supplemented with glucose [10]. These results underline the ability of $H$. mediterranei to use DCB hydrolysate as an inexpensive and sustainable carbon source for the accumulation of $\mathrm{P}(3 \mathrm{HB}-\mathrm{co}-3 \mathrm{HV})$ copolymers without any precursor supplementation.

\subsection{Upscaling of PHA and Carotenoid Co-Production in a Fermenter}

Although C. necator KCTC 2649 exhibited the highest PHA production in shake flask culture, $H$. mediterranei DSM 1411 was selected for batch cultivation in the fermenter owing to its ability to produce $\mathrm{P}(3 \mathrm{HB}-\mathrm{co}-3 \mathrm{HV})$ copolymers. In fact, $\mathrm{P}(3 \mathrm{HB}-\mathrm{co}-3 \mathrm{HV})$ copolymers with a high $3 \mathrm{HV}$ molar ratio are usually required for the processing of bioplastic materials with high mechanical and thermal properties. Moreover, along with $\mathrm{P}$ (3HB-co-3HV) copolymer accumulation, $H$. mediterranei DSM 1411 was able to produce carotenoids as high-value products, which may reduce the overall cost of PHA production.

Batch fermentation of $H$. mediterranei DSM 1411 was performed in a $1 \mathrm{~L}$ working volume fermenter under specific conditions of temperature, $\mathrm{pH}$, aeration, and agitation. Figure 6 shows the cell growth profile, carotenoid production, PHA accumulation, and substrate utilization by $H$. mediterranei DSM 1411 during $144 \mathrm{~h}$ of cultivation in the fermenter. PHA production began during the exponential growth phase and continuously increased as cell biomass increased, reaching a maximum level of $5.50 \pm 0.21 \mathrm{~g} / \mathrm{L}(58.4 \%$ of DCW) at the beginning of the stationary phase with a carotenoid co-production of $2.48 \pm 0.18 \mathrm{mg} / \mathrm{L}$. In fact, during the stationary phase, cell division ends and cells start the process of polymer accumulation induced by the excess of carbon source and nitrogen-limiting conditions [34]. The DCW and PHA levels recorded in this study were respectively $148 \%$ and $150 \%$ higher than those obtained by Ghosh et al. [7] when the same strain was cultivated in the presence of $25 \%(w / w)$ of Ulva sp. hydrolysate. This difference in terms of PHA production can be attributed to the difference in carbohydrate composition between the two algal biomasses as well as to the presence of toxic fermentation inhibitors in Ulva sp. biomass hydrolysate (1.3 mg of 5-hydroxymethylfurfural per gram of dried macroalgal biomass) that may affect cell growth and thus PHA accumulation. Although a higher carotenoid concentration of $11.7 \mathrm{mg} / \mathrm{L}$ was reported by Khomlaem et al. [10] when upscaling the bioconversion of $\mathrm{HCl}$ DCB hydrolysate to a $3 \mathrm{~L}$ working volume fermenter by Paracoccus sp. LL1, PHA content accumulated by $H$. mediterranei in this work was 1.5-fold higher. Our results demonstrate the high potential of $H$. mediterranei in converting DCB-hydrolysate-derived sugars into $\mathrm{P}(3 \mathrm{HB}-\mathrm{co}-3 \mathrm{HV})$ without any precursor supplementation. These findings are of great importance, as the cultivated strain was able to convert reducing sugars from an inexpensive substrate into a $\mathrm{P}$ (3HB-co-3HV) copolymer with higher functionality compared with a PHB homopolymer. 


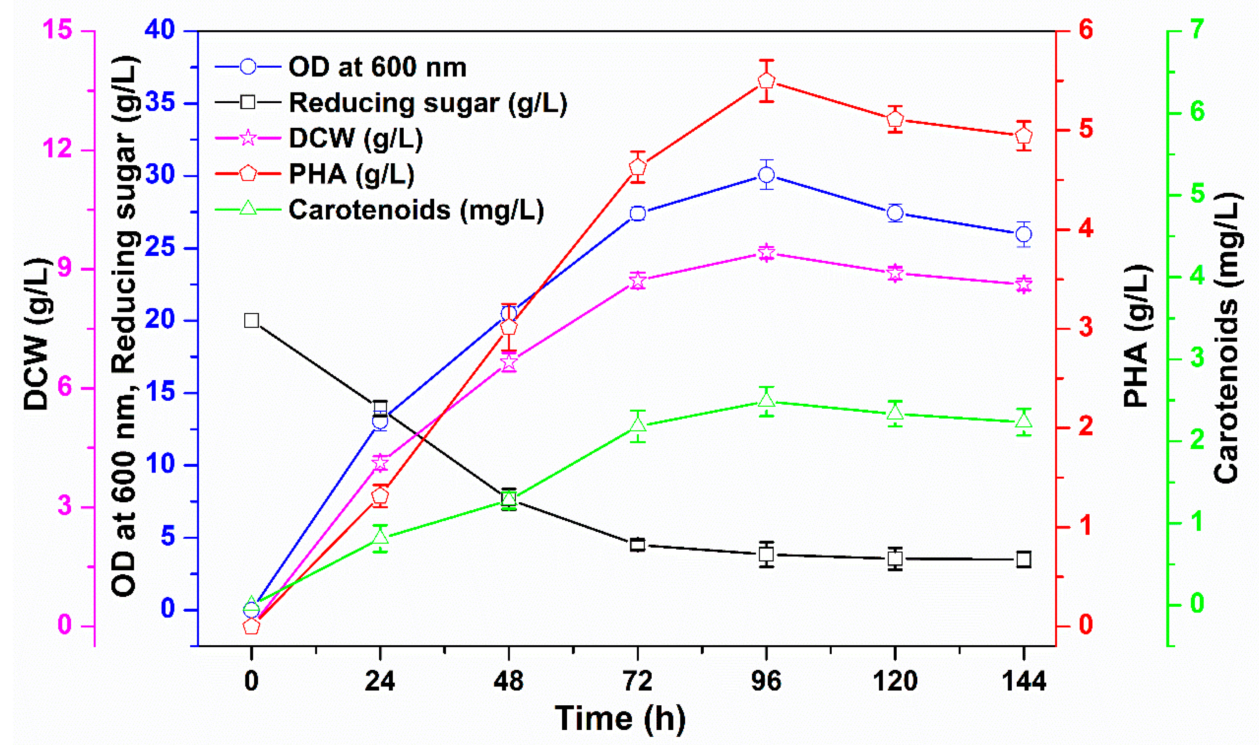

Figure 6. Time profile of OD at $600 \mathrm{~nm}$, DCW, PHA accumulation, carotenoid production, and substrate utilization by Haloferax mediterranei DSM 1411 using $0.3 \mathrm{~N} \mathrm{HCl} \mathrm{DCB} \mathrm{hydrolysate} \mathrm{as} \mathrm{the}$ carbon source in the fermenter. Data are shown as mean values \pm standard deviation $(n=3)$.

\section{Conclusions}

In this work, DCB-hydrolysate-derived sugars were successfully converted into PHA by Cupriavidus necator KCTC 2649, Bacillus megaterium ALA2, and Haloferax mediterranei DSM 1411. C. necator exhibited a maximum PHA production of $7.51 \pm 0.20 \mathrm{~g} / \mathrm{L}(75.4 \%$ of DCW) at $120 \mathrm{~h}$ of cultivation. Along with PHA accumulation, a maximum carotenoid content of $1.80 \pm 0.16 \mathrm{mg} / \mathrm{L}$ was produced by $H$. mediterranei DSM 1411 at $120 \mathrm{~h}$ of cultivation in shake flasks. PHA and carotenoid production respectively increased by 1.45- and 1.37-fold when $\mathrm{HCl} \mathrm{DCB}$ hydrolysate biotransformation was upscaled to a $1 \mathrm{~L}$ working volume fermenter. Taking into account the overall results of this study, DCB can be investigated as a sustainable substrate to reduce the high production cost related to bioplastic production, along with limiting environmental problems arising from waste disposal.

Author Contributions: Methodology and investigation, C.K. and H.A.; formal analysis and data curation, C.K.; writing - original draft and data analysis, H.A.; conceptualization, supervision, and writing-review \& editing, B.S.K. All authors have read and agreed to the published version of the manuscript.

Funding: This research was supported by the National Research Foundation of Korea (NRF2019R111A3A02058523).

Institutional Review Board Statement: Not applicable.

Informed Consent Statement: Not applicable.

Data Availability Statement: The data presented in this study are available on request from the corresponding authors.

Acknowledgments: We would like to thank Ching T. Hou at National Center for Agricultural Utilization Research, ARS, USDA for supplying Bacillus megaterium ALA2 strain.

Conflicts of Interest: The authors declare no conflict of interest. 


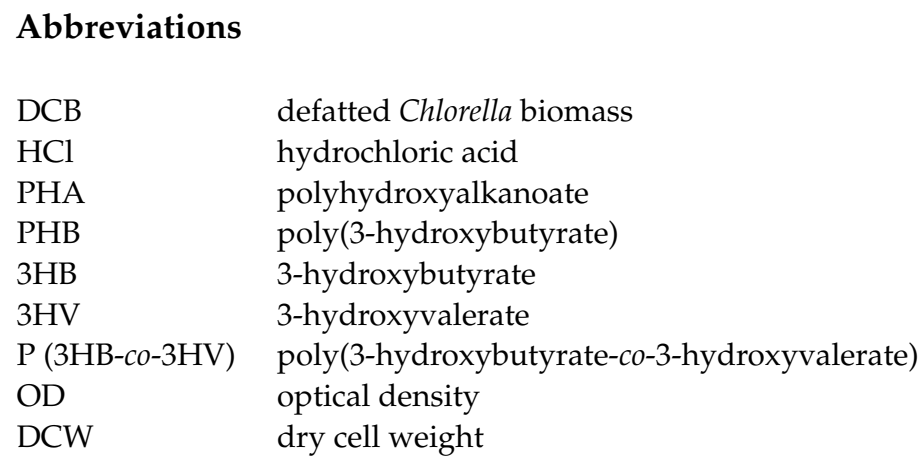

\section{References}

1. Rabnawaz, M.; Wyman, I.; Auras, R.; Cheng, S. A roadmap towards green packaging: The current status and future outlook for polyesters in the packaging industry. Green Chem. 2017, 19, 4737-4753. [CrossRef]

2. Saratale, R.G.; Saratale, G.D.; Cho, S.K.; Kim, D.S.; Ghodake, G.S.; Kadam, A.; Kumar, G.; Bharagava, R.N.; Banu, R.; Shin, H.S. Pretreatment of kenaf (Hibiscus cannabinus L.) biomass feedstock for polyhydroxybutyrate (PHB) production and characterization. Bioresour. Technol. 2019, 282, 75-80. [CrossRef] [PubMed]

3. Huang, T.Y.; Duan, K.J.; Huang, S.Y.; Chen, C.W. Production of polyhydroxyalkanoates from inexpensive extruded rice bran and starch by Haloferax mediterranei. J. Ind. Microbiol. Biotechnol. 2006, 33, 701-706. [CrossRef] [PubMed]

4. $\quad$ Bhatia, S.K.; Gurav, R.; Choi, T.R.; Jung, H.R.; Yang, S.Y.; Moon, Y.M.; Song, H.S.; Jeon, J.M.; Choi, K.Y.; Yang, Y.H. Bioconversion of plant biomass hydrolysate into bioplastic (polyhydroxyalkanoates) using Ralstonia eutropha 5119. Bioresour. Technol. 2019, 271, 306-315. [CrossRef] [PubMed]

5. Kumar, P.; Kim, B.S. Paracoccus sp. strain LL1 as a single cell factory for the conversion of waste cooking oil to polyhydroxyalkanoates and carotenoids. Appl. Food Biotechnol. 2019, 6, 53-60. [CrossRef]

6. Bhatia, S.K.; Kim, J.H.; Kim, M.S.; Kim, J.; Hong, J.W.; Hong, Y.G.; Kim, H.J.; Jeon, J.M.; Kim, S.H.; Ahn, J.; et al. Production of (3-hydroxybutyrate-co-3-hydroxyhexanoate) copolymer from coffee waste oil using engineered Ralstonia eutropha. Bioprocess. Biosyst. Eng. 2018, 41, 229-235. [CrossRef]

7. Ghosh, S.; Gnaim, R.; Greiserman, S.; Fadeev, L.; Gozin, M.; Golberg, A. Macroalgal biomass subcritical hydrolysates for the production of polyhydroxyalkanoate (PHA) by Haloferax mediterranei. Bioresour. Technol. 2019, 271, 166-173. [CrossRef]

8. Azizi, N.; Najafpour, G.; Younesi, H. Acid pretreatment and enzymatic saccharification of brown seaweed for polyhydroxybutyrate (PHB) production using Cupriavidus necator. Int. J. Biol. Macromol. 2017, 101, 1029-1040. [CrossRef]

9. Alkotaini, B.; Koo, H.; Kim, B.S. Production of polyhydroxyalkanoates by batch and fed-batch cultivations of Bacillus megaterium from acid-treated red algae. Korean J. Chem. Eng. 2016, 33, 1669-1673. [CrossRef]

10. Khomlaem, C.; Aloui, H.; Deshmukh, A.R.; Yun, J.-H.; Kim, H.-S.; Napathorn, S.C.; Kim, B.S. Defatted Chlorella biomass as a renewable carbon source for polyhydroxyalkanoates and carotenoids co-production. Algal Res. 2020, 51, 102068. [CrossRef]

11. Guccione, A.; Biondi, N.; Sampietro, G.; Rodolfi, L.; Bassi, N.; Tredici, M.R. Chlorella for protein and biofuels: From strain selection to outdoor cultivation in a Green Wall Panel photobioreactor. Biotechnol. Biofuels 2014, 7, 84. [CrossRef] [PubMed]

12. Prommuak, C.; Pavasant, P.; Quitain, A.T.; Goto, M.; Shotipruk, A. Simultaneous Production of Biodiesel and Free Lutein from Chlorella vulgaris. Chem. Eng. Technol. 2013, 36, 733-739. [CrossRef]

13. Agwa, O.K.; Nwosu, I.G.; Abu, G.O. Bioethanol Production from Chlorella vulgaris Biomass Cultivated with Plantain (Musa paradisiaca) Peels Extract. Adv. Biosci. Biotechnol. 2017, 08, 478-490. [CrossRef]

14. Al-lwayzy, S.H.; Yusaf, T.; Al-Juboori, R.A. Biofuels from the fresh water microalgae Chlorella vulgaris (FWM-CV) for diesel engines. Energies 2014, 7, 1829-1851. [CrossRef]

15. Muhammad, M.; Aloui, H.; Khomlaem, C.; Hou, C.T.; Kim, B.S. Production of polyhydroxyalkanoates and carotenoids through cultivation of different bacterial strains using brown algae hydrolysate as a carbon source. Biocatal. Agric. Biotechnol. 2020, 30, 101852. [CrossRef]

16. Kim, B.S.; Kim, H.R.; Hou, C.T. Effect of surfactant on the production of oxygenated unsaturated fatty acids by Bacillus megaterium ALA2. New Biotechnol. 2010, 27, 33-37. [CrossRef]

17. Melanie, S.; Winterburn, J.B.; Devianto, H. Production of Biopolymer Polyhydroxyalkanoates (PHA) by Extreme Halophilic Marine Archaea Haloferax mediterranei in Medium with Varying Phosphorus Concentration. J. Eng. Technol. Sci. 2018, 50, 255-271. [CrossRef]

18. Gouda, M.K.; Swellam, A.E.; Omar, S.H. Production of PHB by a Bacillus megaterium strain using sugarcane molasses and corn steep liquor as sole carbon and nitrogen sources. Microbiol. Res. 2001, 156, 201-207. [CrossRef]

19. Kim, N.J.; Li, H.; Jung, K.; Chang, H.N.; Lee, P.C. Ethanol production from marine algal hydrolysates using Escherichia coli KO11. Bioresour. Technol. 2011, 102, 7466-7469. [CrossRef]

20. Nygaard, D.; Yashchuk, O.; Hermida, É.B. Evaluation of culture medium on poly(3-hydroxybutyrate) production by Cupriavidus necator ATCC 17697: Application of the response surface methodology. Heliyon 2019, 5, 1-18. [CrossRef] 
21. Verlinden, R.A.J.; Hill, D.J.; Kenward, M.A.; Williams, C.D.; Piotrowska-Seget, Z.; Radecka, I.K. Production of polyhydroxyalkanoates from waste frying oil by Cupriavidus necator. AMB Express 2011, 1, 11. [CrossRef] [PubMed]

22. Sen, K.Y.; Hussin, M.H.; Baidurah, S. Biosynthesis of poly(3-hydroxybutyrate) (PHB) by Cupriavidus necator from various pretreated molasses as carbon source. Biocatal. Agric. Biotechnol. 2019, 17, 51-59. [CrossRef]

23. Ferre-Guell, A.; Winterburn, J. Increased production of polyhydroxyalkanoates with controllable composition and consistent material properties by fed-batch fermentation. Biochem. Eng. J. 2019, 141, 35-42. [CrossRef]

24. Zuo, Z.Q.; Xue, Q.; Zhou, J.; Zhao, D.H.; Han, J.; Xiang, H. Engineering Haloferax mediterranei as an efficient platform for high level production of lycopene. Front. Microbiol. 2018, 9, 1-13. [CrossRef] [PubMed]

25. Pais, J.; Serafim, L.S.; Freitas, F.; Reis, M.A.M. Conversion of cheese whey into poly(3-hydroxybutyrate-co-3-hydroxyvalerate) by Haloferax mediterranei. New Biotechnol. 2016, 33, 224-230. [CrossRef]

26. Bhattacharyya, A.; Saha, J.; Haldar, S.; Bhowmic, A.; Mukhopadhyay, U.K.; Mukherjee, J. Production of poly-3-(hydroxybutyrateco-hydroxyvalerate) by Haloferax mediterranei using rice-based ethanol stillage with simultaneous recovery and re-use of medium salts. Extremophiles 2014, 18, 463-470. [CrossRef]

27. Ansari, S.; Fatma, T. Cyanobacterial Polyhydroxybutyrate (PHB): Screening, Optimization and Characterization. PLoS ONE 2016, 11, e0158168. [CrossRef]

28. Alsafadi, D.; Al-Mashaqbeh, O. A one-stage cultivation process for the production of poly-3-(hydroxybutyrate-cohydroxyvalerate) from olive mill wastewater by Haloferax mediterranei. New Biotechnol. 2017, 34, 47-53. [CrossRef]

29. Raho, S.; Carofiglio, V.E.; Montemurro, M.; Miceli, V.; Centrone, D.; Stufano, P.; Schioppa, M.; Pontonio, E.; Rizzello, C.G. Production of the polyhydroxyalkanoate PHBV from ricotta cheese exhausted whey by Haloferax mediterranei fermentation. Foods 2020, 9, 1459. [CrossRef]

30. Gahlawat, G.; Soni, S.K. Valorization of waste glycerol for the production of poly (3-hydroxybutyrate) and poly (3hydroxybutyrate-co-3-hydroxyvalerate) copolymer by Cupriavidus necator and extraction in a sustainable manner. Bioresour. Technol. 2017, 243, 492-501. [CrossRef]

31. Alsafadi, D.; Ibrahim, M.I.; Alamry, K.A.; Hussein, M.A.; Mansour, A. Utilizing the crop waste of date palm fruit to biosynthesize polyhydroxyalkanoate bioplastics with favorable properties. Sci. Total Environ. 2020, 737, 139716. [CrossRef] [PubMed]

32. Koller, M. Recycling of waste streams of the biotechnological poly(hydroxyalkanoate) production by Haloferax mediterranei on whey. Int. J. Polym. Sci. 2015, 2015. [CrossRef]

33. Koller, M.; Puppi, D.; Braunegg, F. Comparing Chemical and Enzymatic Hydrolysis of Whey Lactose to Generate Feedstocks for Haloarchaeal Poly(3-hydroxybutyrate-co-3- hydroxyvalerate) Biosynthesis. Int. J. Pharm. Sci. Res. 2016, 3. [CrossRef] [PubMed]

34. López-Cuellar, M.R.; Alba-Flores, J.; Rodríguez, J.N.G.; Pérez-Guevara, F. Production of polyhydroxyalkanoates (PHAs) with canola oil as carbon source. Int. J. Biol. Macromol. 2011, 48, 74-80. [CrossRef] [PubMed] 